\title{
Influence of reproductively significant autoantibodies on the quality of oocytes, obtained embryos and the chances of implantation in Assisted Reproductive Technologies cycles. Literature review ${ }^{\star}$
}

\author{
G. Kh.Safarian ${ }^{1}$, A.M. Gzgzyan ${ }^{1,2}$, L. Kh. Dzhemlikhanova ${ }^{1,2}$, \\ D. A. Niauri, ${ }^{1,2}$, A. V.Znobishina ${ }^{1}$, Ye. S. Borodina ${ }^{1}$, T. C. Nguyen ${ }^{1}$ \\ ${ }^{1}$ St. Petersburg State University, \\ 7-9, Universitetskaya nab., St. Petersburg, 199034, Russian Federation \\ 2 D. O. Ott Research Institute of Obstetrics, Gynecology and Reproductology, \\ 3, Mendeleevskaya lin., St. Petersburg, 199034, Russian Federation
}

For citation: Safarian G. Kh., Gzgzyan A.M., Dzhemlikhanova L. Kh., Niauri D. A., Znobishina A. V., Borodina Ye. S., Nguyen T.C. Influence of reproductively significant autoantibodies on the quality of oocytes, obtained embryos and the chances of implantation in Assisted Reproductive Technologies cycles. Literature review. Vestnik of Saint Petersburg University. Medicine, 2020, vol. 15, issue 4, pp. 256-273. https://doi.org/10.21638/spbu11.2020.404

There is evidence suggesting that autoimmune mechanisms may influence fertility, manifesting as infertility or pregnancy loss. Numerous autoimmune diseases, including but not limited to systemic lupus erythematosus, anti-phospholipid syndrome and Hashimoto thyroiditis may be associated with infertility and pregnancy loss through different putative mechanisms. It is notable that fertility may be impaired in the presence of serum autoantibodies regardless of the presence of a clinically overt autoimmune disease. Autoimmunity may affect all stages of fertility via ovarian failure, implantation failure, and pregnancy loss. This review article will illustrate and discuss the available data on the link between chances of achieving pregnancy through Assisted Reproductive Technologies in real clinical setting in the presence of several autoantibodies affecting female reproductive system. Summarizing the available data from the world literature, it can be concluded that necessity exist in development of a reproductively significant antibodies line in application to direct, cross-over and cumulative assessment of the role of autoimmune antibodies carriage in the implementation of reproductive failures,

* The work is supported by a grant from the Government of the Russian Federation (contract 14.W03.31.0009 of 13.02.2017) for state support of scientific research conducted under the supervision of leading scientists.

(C) St. Petersburg State University, 2020 
bearing in mind new approaches to the strategy of overcoming autoimmune reproductive failure.

Keywords: autoantibodies, TPO, APA, ANA, a-enolase, laminin-1, Se-binding protein 1.

\section{Introduction}

Prevalence of barrenness within marriage remains at stably high level (8-15\%), despite of the active introduction and availability of assisted reproductive technologies (ART) [1-4].

According to European Society of Human Reproduction and Embryology (ESHRE), the cause of barrenness remains unknown in 10-20\% cases [5]. Infertility and unfavorable results of In vitro fertilization (IVF) using Intra cytoplasmic sperm injection (ICSI) in case of autoimmune diseases is the object of deliberate attention and increases interest of many investigators [6-10]. Notable the fact that in women diagnosed with idiopathic infertility increased level of serum antiphospholipid antibodies, antinuclear antibodies and antibodies to thyroid gland tissue are often detected [9; 11-17]. Autoimmune disorders are also widely discussed last years and are considered etiological factors in implantation failure development $[8 ; 18-28]$. Besides, according to reports of some investigators, presence of circulating serum antibodies may result in development of premature ovarian insufficiency $[3 ; 19 ; 29-34]$. The role of cellular immunity in repeated implantation failures in course of IVF/ICSI programs in patients with infertility and autoimmune diseases is studied [35;36]. From the above-listed it becomes obvious that there is an existence of various autoimmune mechanisms impacting the female reproductive potential.

Thereby, the purpose of this survey article is to study evidence based on available world literature concerning the influence of different antibodies on female fertility with the aim to perform comprehensive analysis of possible associations between antibodies carrier state and successfulness of infertility treatment using assisted reproductive technologies (ART). The analysis concerns the most prevailing antibodies, about the influence of which on reproductive system was reported earlier including antithyroid, antiphospholipid, antinuclear antibodies, as well as less known antibodies to laminin-1, $\alpha$-enolase-1, beta-hCG, aromatase, Se-binding protein-1 (SBP-1) and to mesothelin.

\section{Anti-thyroid antibodies}

It is known, that Graves' disease (GD), occurring with thyrotoxicosis, and autoimmune thyroiditis (AIT), being the main cause of hypothyroidism, may alter the function of female reproductive system causing menstrual irregularities, infertility and recurrent miscarriage [37-39]. In prevailing majority of patients diagnostically significant autoantibodies to thyroperoxidase (AT-TPO), thyroglobulin (AT-TG), and to some other colloid and cytoplasmic autoantigenes were detected. It is interesting to note, that among women with infertility of unknown origin the prevalence of autoimmune thyroiditis constitutes approximately $10 \%$ [9]. It is important to note that antibodies carrier state with normal thyroid function among women of reproductive age constitutes at average $8-14 \%$ [40] and is often not diagnosed due to the absence of typical clinical symptoms of the disease. 
In accessible literature results of possible mechanisms of isolated antibodies to thyroperoxidase (AT-TPO) and to thyroglobulin (AT-TG) carrier state on the state of reproductive system are presented [11-13; 41-42].

According to the theory of Monteleone et al. (2011), female infertility associated with autoimmune thyroiditis may be caused by the changes in the structures of follicles [11]. Presence of AT-TG and AT-TPO was detected in all samples of female follicular fluid with AIT. Moreover, there was clear correlation with the level of serum antibodies indicating on their ability to pass freely through blood-follicle barrier. To the author's opinion, anti-thyroid antibodies may exert direct toxic effect on the growing follicle and adversely affect the quality of future embryo due to the direct interaction with zona pellucida antigens, disordering its functional role. Indeed, in the performed investigation the fertilization rate, number of good quality embryos and clinical pregnancy rate were considerably lower in the main group when compared with controls. These data enables to propose a direct impact of antithyroid antibodies on ovarian tissue. Later, it was reported that after the exclusion from investigation of women with a known cause of diminished ovarian reserve, the frequency of AT-TPO carrier state considerably differed among women with decreased $(22.7 \%)$, normal $(14.0 \%)$ and high $(10.3 \%, p=0.012)$ ovarian reserve [12].

Data exists that in women - carriers of antithyroid antibodies the quality of embryos, obtained in assisted reproductive technology (ART) programs, frequently suffers. So Werghofer et.al. performed case-control study investigating AIT effect on embryo quality, obtained during intra cytoplasmic sperm injection (ICSI) among women with decreased ovarian reserve [41]. Embryos were described in accordance with Gardner DK criteria (2003). Downtrend in embryo quality was detected in women from study group, regardless of thyroid stimulating hormone (TSH) level $(\mathrm{p}=0.056)$. Obtained results find a reflection in the theory of Monteleone et. al. (2011), and, extremely important, underlines key effect, namely of antibodies, but not hypothyroidism, on the results of IVF/ICSI procedures.

A number of authors also performed studies on treatment results using assisted reproductive technologies $[9 ; 18 ; 43 ; 44]$. ART outcomes were investigated by Medenica et al. [43] among in total of 52 women (26 TAI positive subjects and 26 age and body mass index matched TAI negative controls). Twenty patients were on levothyroxine substitution (mean daily levothyroxine dose was $67.49 \pm 29.40 \mathrm{mcg}$, treatment duration was 19.50 months). According to obtained results, no statistically significant difference between the number of oocytes retrieved and fertilization rate in compared groups was revealed. But the implantation rate was considerably lower in the group of patients with AIT when compared with control group (21.01 vs to $31.94 \%, \mathrm{p}=0.005)$.

Similar data were obtained in the retrospective study of Zhong et al. [18] including a total of 90 patients (156 cycles) positive for antithyroid antibody and 676 infertile women (1062 cycles) negative for antithyroid antibody, undergoing IVF/ICSI. were included. The number of oocytes retrieved was comparable between these groups. But fertilization rate (64.3 vs $74.6 \%, \mathrm{p}<0.001)$ and implantation rate $(17.8$ vs $27.1 \%, \mathrm{p}<0.001)$ were significantly lower in the group of patients with AIT in comparison to the control group. Nevertheless, the authors did not report on thyroid-stimulating hormone levels before starting stimulation.

However, contrary data also exist. Based on systematic review of nine articles, investigating the results of IVF/ICSI cycles among 4396 women - carriers of anti-thyroid antibodies, Busnelli et al. revealed the absence of difference in the number of oocytes 
retrieved $(\mathrm{p}=0.28)$, fertilization rate $(\mathrm{p}=0.13)$ and implantation rate $(\mathrm{p}=0.91)$ among AT-TPO carriers within fertility treatment program in respect to control group [44]. The authors themselves, using the theory of Monteleone et al. [11], consider that the possible reason in the absence of any difference in fertilization and implantation rates between the compared groups was the analysis of these indicators only in ICSI protocols, but not conventional IVF protocols. On the basis of this assumption they suggested a theory that it is possible to bypass negative impact of antithyroid antibodies at zona pellucida by performing ICSI procedure.

In support to their opinion, Poppe at el. performed meta-analysis of four studies devoted to the results of ICSI procedures among women with subclinical hypothyroidism and TAI [9] in comparison to healthy infertile women and did not reveal any differences in fertilization rate $(\mathrm{p}=0.09)$ and implantation rate $(\mathrm{p}=0.92)$. Thereby, the theory suggested in 2016 [44] may appeared rather reasonable, considering the results obtained in 2018 [9].

\section{Antiphospholipid antibodies}

Antiphospholipid syndrome (APS) represents one of the most prevalent acquired trombophilia and causes venous, arterial and microvascular thrombosis and is characterized by the antiphospholipid antibodies (aPL) presence, mainly lupus anticoagulant (LA), anticardiolipin antibodies (aCL) and antibodies to $\beta 2$ glycoprotein-I ( $\beta-2 \mathrm{GPI})$, directed against negatively charged phospholipids [45]. Anti-phospholipid syndrome is associated with systemic lupus erythematosus (SLE) in about $35 \%$ cases, lupus-like syndrome is observed in $5 \%$ of patients. Average age of the disease debut constitutes 31 years with ratio of female to male patients $5 / 1[45 ; 46]$.

If aPL role in recurrent pregnancy loss is obvious [47-49], its role in infertility and IVF failures remains debatable. For the first time hypothesis concerning harmful effects of antiphospholipid antibodies on female fertility was suggested in 1980s years [50]. At present time there are available data that among 8-9\% of women with infertility of unknown origin and multiple IVF failures more than one type of antiphospholipid antibodies are determined when compared with $1.5 \%$ in control group of fertile women $(p=0.0001)$ [14]. According to another sources, aPL are present in 15-59\% of women with idiopathic infertility [15]. After almost a decade Blank et al. in an experimental study demonstrated, that in mice earlier non immunized with anticardiolipin antibodies, after injection of immunoglobulin IgM \& IgG to cardiolipin, a delay in fertilization and in clinical pregnancy rate was observed, while the rate of embryo resorption was increased [51].

The question of antiphospholipid antibodies influence on the embryo implantation and invasion step remains opened and debatable. Impaired angiogenesis in endometrium may be responsible for decreased endometrium receptivity and implantation disturbances. Using experimental models by injecting monoclonal antiphospholipid antibodies to naïve mice a direct negative APA effect on embryo development $[52 ; 53]$ and on endometrium was revealed [54]. Sthoeger at el. reported that injection of mice with monoclonal antibodies to cardiolipin resulted in implantation failure due to binding APA with trophectoderm cells [53]. Kaider et al. demonstrated a delay in embryo development or even death, when cultivated with antiphospholipid antibodies IgG, in comparison to embryos, cultivated with control Ig [52]. Tartakovsky et al. reported that embryos obtained from mice after injected with monoclonal IgG APA, lost ability to implantation after their re- 
moval from media with antiphospholipid antibodies and placing them into uterus of the mice who did not receive APA injection [54].

Besides, in some experimental studies using immunohistochemistry analysis, antiphospholipid antibodies of IgG \& IgA classes were detected around endometrial glands, inside extracellular space of lamina propria and other structures. Levels of IgA 3-4 times exceeded the amount of IgG and total levels of immunoglobulin considerably increased from $1^{\text {st }}$ to $5^{\text {th }}$ day of pregnancy [55].

It is notable, that among women undergoing IVF, disorders in pre-implantation embryo morphology were detected in $50 \%$ of patients with high serum anti-cardiolipin antibody levels in comparison to $20 \%$ of patients without aCL [56]. It may be explained by proven fact of immunoglobulin detection in the follicular fluid, because in a number of experimental studies and clinical investigations, performed on patients after IVF, identification and dynamics of changes in IgG, IgA, IgM concentrations alone with the other immunological indicators was carried out. In a study, performed by Matsubayashi, content of IgG APA in follicular fluid of patients with multiple IVF failures was studied. In all patients positive for antiphospholipid antibodies IgG, immunoglobulins were detected in the follicular fluid [57].

Increased interest to APA influence on pregnancy achieved through assisted reproductive technologies resulted in multiple clinical investigations devoted to relation of APA presence and multiple IVF failures.

In the study of Coulam C.B. the frequency of APA among women with negative pregnancy test after IVF treatment and with biochemical pregnancies was studied. As a result, the rate of APA detection in women with bio-chemical pregnancies was reliably higher than in nonpregnant women $(80$ and $28 \%$ respectively; $\mathrm{p}<0.0001)$ [58]. The authors supposed that the reason of pregnancy interruption lays in altered angiogenesis, and in concordance to other studies $[59 ; 60]$ confirms the role of APA in early reproductive losses.

In a cohort prospective study on APA influence on the results of the first IVF protocol among 1720 infertile women, antibodies to cardiolipin IgG (aCL-IgG) were detected in $11.2 \%$ patients, aCL-IgM - in $1.3 \%$, antibodies IgG to $\beta 2$-glycoprotein ( $\beta 2 \mathrm{GPII}$ ) were found in $11.7 \%$, and IgM- $\beta 2$ GPII in $10.3 \%$ cases. Control group included 844 women without antibodies. By the result of embryological protocols, both groups appeared comparable in number and quality of oocytes retrieved and the fertilization rate. At the same time, lower implantation rate $(23.5 \mathrm{vs} 42.7 \%, \mathrm{p}<0.05)$ and clinical pregnancy rate ( $36.4 \mathrm{vs}$ $61.0 \%, \mathrm{p}<0.05)$ in the group of patients with IgG $-\beta 2 \mathrm{GPII}$ [3] was noted.

In the study of Kikuchi at el. [16] a reliable decrease of IVF efficiency after the first treatment cycle in women with APA was detected. Implantation rate after the first embryo transfer constituted $14.8 \%$ as compared with APA-negative women $(32.4 \%, \mathrm{p}<0.005)$. But cumulative IVF efficiency in both groups turned out to be the same in next protocols. The authors concluded that the presence of antiphospholipid antibodies results in decreased IVF efficiency only in stimulation protocol, but does not influence the cumulative efficiency, and recommend efficient and safe preparations assignment in order to improve implantation rate.

Thereby, the role of antiphospholipid antibodies in development of ART program failures is not fully determined, but this question is extremely relevant for a wide range of researchers and clinicians. 


\section{Antinuclear antibodies}

Represent a group of autoantibodies to proteins and other components, located in cell nucleus and are detected in over than $90 \%$ patients with systemic connective tissue diseases, such as systemic lupus erythematosus (SLE), systemic sclerosis (SS), Sjögren's Syndrome (SS), mixed connective tissue disease (MCTD), polymyositis/dermatomyositis $(\mathrm{PM} / \mathrm{DM})$. It is necessary to notice, that spectrum of antinuclear antibodies (ANA) include a big group of antibodies to dsDNA, nucleoproteins, histones, nuclear RNP and other nuclear components.

It is well known that antinuclear antibodies are involved in pathogenesis of a number of systemic autoimmune diseases [61-66].

The data presented in literature indicate that antinuclear antibodies presence is also connected to immunologically induced infertility. Such, investigations demonstrated that antinuclear antibodies are seen in 20-28.7\% of infertile women undergoing IVF-ET treatment $[16 ; 17]$. Besides that, antinuclear antibodies prevalence constitutes $35.1 \%$ among women with recurrent IVF failure [67] and $27 \%$ among women with endometriosis [68]. Studies exist revealing connection between ANA presence and repeated IVF failure [2023]. Nevertheless, the main mechanisms leading to that are not still completely understood. There is evidence indicating positive correlation between antinuclear antibodies levels in the serum and in the follicular fluid. At the same time a negative correlation between antibody levels with the number of good quality embryos, obtained in IVF/ICSI cycles [69] was noted.

In addition, experimental studies in vivo were carried out when two cell stage mice embryos were co-incubated with purified immunoglobulin IgG. Upon termination, immunofluorescence analysis was performed for antinuclear antibodies detection within embryos and revealed clear fluorescent signal directly in embryos. Moreover, some embryos exerted a delay in development or even total arrest [70]. However, because zona pellucida does not contain nuclear antigens and phospholipids, specific epitope for those antibodies remains unknown [71]. In another experimental study a complete arrest of meiosis after microinjection of anticentromere antibodies IgG (ACA) to rat oocytes occurred [72]. The above-listed enables to suppose that antinuclear antibodies are able to exert direct toxic impact on oocyte and embryo development resulting in infertility.

In available literature the influence of given antibodies on the results of IVF programs are presented $[3 ; 20-23 ; 69 ; 73-76]$. For instance, in 2012 a group of scientists from China evaluated embryo quality obtained during infertility treatment in the presence of antinuclear antibodies detection. The number of mature ovocytes MII ( 68.5 vs $82.6 \%, p<0.001)$, $2 \mathrm{PN}$ (zygotes with two pronuclei) ( 52.4 vs $58.5 \%, \mathrm{p}=0.003$ ) and a number of good quality embryos (22.4 vs $31.8 \%, \mathrm{p}<0.001$ ) appeared considerably lower in the study group (96 cycles) in comparison to the control group ( 285 cycles). Moreover, implantation rate (15 vs $25.7 \%$ ) among patients positive for antinuclear antibodies, significantly differed from that in the ANA negative group. Thus, the authors concluded that antinuclear antibodies presence impairs oocyte maturation, embryo and fetal development resulting in decreased implantation and pregnancy rate in IVF/ICSI programs [69].

In later study of the same authors a reliable decline of ART programs efficiency in the presence of antinuclear antibodies was confirmed again, i. e. less number of high quality embryos, lower implantation rate and clinical pregnancy rate. Besides the fact that 
IgG antibodies were presented in the follicular fluid of seropositive women, they were detected within embryos. Important to notice that the mentioned analysis was carried out exclusively on embryos of poor quality not subjected to transfer preventing further understanding of possible antibody damaging mechanisms on pregnancy onset and development potential [73].

\section{Antibodies to laminin-1}

The influence of antibodies to laminin- 1 on female reproductive potential is discussed more and more frequently in scientific communities. First described in 1978, laminin presents a multifunctional adhesive glycoprotein of basal membranes and thin extracellular matrix and consists of $\alpha$-, $\beta$-, and $\gamma$-chains [77]. It is known, that in early stage human embryo cells laminin-1 increases the expression of type IV collagenase enhancing thophoblast adhesion during peri-implantation period [78]. In humans during the first trimester of pregnancy a- 1 chain of laminin is detected in basal membrane of thophoblast and at the spots of direct contact with the cells of extravillous trophoblast. In the second pregnancy trimester it is present selectively at the places of direct contact between villous basal membrane and proliferating islands of trophoblastic cells [79]. Thereby, laminin-1 may play important role in all the processes associated with embryo implantation, placentation and embryogenesis.

Antibodies to laminin-1 were firstly extracted in 1989 from primates with reproductive function failure, and when cultivated with rat embryos developmental delay in the latter was detected [80]. In later works, experimental models were created in which high titers of antibodies to this antigen were determined in animals after murine laminin-1 injection. The authors noted a tendency towards unsuccessful pregnancy outcomes among the tested animals expressed in a higher frequency of fetal resorption, a decrease in the weight of the placenta and the weight of embryos for a given gestational age [81].

The role of antibodies to laminin- 1 in reproductive failure has also been extensively studied in humans. In the early 2000s, in a clinical study by Inagaki et al. found a significantly higher incidence of recurrent first trimester miscarriages among women carriers of anti-laminin-1 IgG antibodies [24]. A total of 177 women with a history of recurrent miscarriage were tested for antibodies against laminin-1, b2-glycoprotein I (b2-GPI), lupus anticoagulant, antibodies to double-stranded DNA and antinuclear antibodies before the onset of the next pregnancy. Anti-lamini-1 IgG was detected in 55 of 177 women $(31.1 \%)$ with a history of miscarriage. Anti-laminin-1 IgG titers were significantly higher in the test group relative to women with normal pregnancies and healthy non-pregnant women ( $p=0.0043$ and 0.0073 , respectively). Subsequently, the frequency of live births in the laminin-1 group was significantly lower than in the controls $(\mathrm{p}=0.032)$. Thus, the authors suggested that IgG antibodies to laminin-1 exert a direct toxic effect on the earliest stages of pregnancy during embryo implantation, embryogenesis, and active angiogenesis in the placenta.

In the world literature data also exist highlighting the relationship between antibodies to laminin-1 presence with infertility, especially caused by endometriosis ( $29 \%$ of affected women) $[82 ; 83]$. The presence of autoantibodies in the study group significantly correlated with the presence of endometriosis $(\mathrm{p}=0.0096)$. When comparing the mean values of the antibody content in the groups of infertile women with and without endometriosis, higher 
rates were noted among 42 women with endometriosis (mean value $1.1 \pm 1.2 \mathrm{U} / \mathrm{ml}$ ) compared with the control group (mean value $0.46 \pm 0.33 \mathrm{U} / \mathrm{ml})(\mathrm{p}=0.015)$ [82].

It is now also known that laminin-1, along with fibronectin, plays an important role in the maturation of oocytes by accelerating the formation of polar bodies [84]. Based on this, it can be assumed that antibodies to laminin should also be detected in follicular fluid. And, in fact, for the first time, these antibodies were detected in the follicular fluid of women with endometriosis (31\% of examined) by Caccavo et al. in 2011 [83] and positively correlated with serum levels. Based on this fact, the authors suggested that antibodies to laminin-1 are able to freely pass through the blood-follicular barrier. In the same study, the authors revealed a peculiarity: the number of mature MII oocytes negatively correlated with the level of antibodies in the follicular fluid ( $p=0.0006)$. At the same time, the frequency of ongoing pregnancy did not differ significantly among women with or without circulating antibodies ( 36 vs $29 \%, p=0.7$ ), which led to the conclusion that there was no negative effect of AT-laminin-1 on the effectiveness of the IVF procedure.

In a later research of the same scientists for the first time the fact of high titers of antibodies to laminin-1 in the sera of women with AIT (19/44 - 43.2\%) compared with the control group $(1 / 28-3.6 \%)$ was reported. In IVF cycles, a negative correlation was found between the number of mature oocytes and the level of AT-laminin-1 in the follicular fluid $(p=0.03)$. However, the incidence of implantation rate and clinical pregnancy rate was much lower in the group of patients with AIT $(\mathrm{p}=0.015)$ compared with the control group $(\mathrm{p}=0.03)$. Thus, a negative influence of AT-laminin-1 along with AT-TPO on the results of IVF cycles was revealed [84].

\section{Antibodies to $\alpha$-enolase-1}

In 2018, a group of German scientists conducted a study to identify antibodies involved in recurrent miscarriage. Using Western blotting and mass spectrometry, the authors discovered a new target for antibodies to trophoblast, namely enolase-1 (ENO1), which is detected in the JEG-3 choriocarcinoma cell line as well as in the tissue of extravillous trophoblast of the first trimester of pregnancy [25]. As known, ENO1 is a multifunctional glycolytic enzyme weighing $45-47 \mathrm{kDa}$ and is abundant in the cytoplasm of different cells. It has been proven that antibodies to enolase- 1 are present in some autoimmune diseases, such as rheumatoid arthritis, systemic lupus erythematosus, systemic sclerosis, Behcet's disease, ulcerative colitis, Crohn's disease, and primary sclerosing cholangitis [85]. The relationship between the carriage of these antibodies with endometriosis and premature ovarian failure is also being discussed [86; 87]. Sarapik et al. revealed a higher incidence of antibodies to enolase-1 IgA among women with peritoneal infertility [86]. According to other opinions, ENO1 represents a specific antigen for anti-endometrial antibodies [87]. The serum values were significantly higher among women with recurrent miscarriage when compared with the control group. Thus, there are numerous reports on the negative effect of antibodies to enolase- 1 on female reproductive health.

It is known that antibodies to enolase- 1 are found in large quantities in the decidual tissue of the first trimester placenta (about 9 weeks of gestation) among women with a history of recurrent miscarriage. Moreover, in vitro, antibodies against ENO1 inhibited the production of $\beta$-hCG and progesterone by the cells of the human villous trophoblast. Thus, the authors suggest that these antibodies may become a new autoimmune biomarker 
for recurrent miscarriage [25]. In addition, along with the presence of antibodies to enolase-1, elevated serum levels of proinflammatory cytokines such as IL- $1 \beta$, TNF- $\alpha$, and PGE2 were detected, negatively affecting the development of pregnancy [85].

There are also studies on the relationship of antibodies to enolase- 1 with the premature ovarian failure. When evaluating sera of 110 women with this diagnosis, antibodies to $\alpha$-enolase-1 were detected in 21 of them (19.1\%) [31]. The authors suggested that the development of ovarian failure among patients with identified antibodies is based on defects in systemic immunoregulation, which may appear before, during or after the onset of another autoimmune disease. The antibodies themselves, in this case, are considered an indicator of the autoimmune etiology of ovarian insufficiency and can be used as a diagnostic marker of the disease.

Despite the available data on the negative effect of antibodies to enolase- 1 on the course of early pregnancy $[25 ; 87]$, at present there are practically no studies evaluating the effectiveness of ART programs in the presence of the mentioned antibodies.

\section{Antibodies to HCG}

In a number of studies, antibodies to hCG are considered as a possible cause of miscarriage, infertility and IVF cycles failures [88-90].

In one of the studies, carriers of antibodies to hCG had a lower pregnancy rate and an increased frequency of spontaneous miscarriages after IVF treatment in comparison to negative control group. These frequency rates were comparable to those observed in women with antiphospholipid antibodies and antitrophoblast antibodies. Thus, the authors pointed on the need to determine antibodies to hCG in patients undergoing IVF [90]. However, to date, there are no large studies and a sufficient evidence indicating a negative effect of antibodies to hCG on the effectiveness of ART programs.

\section{Antibodies to aromatase}

Aromatase is an enzyme complex that converts androgens into estrogens and consists of two components: aromatase of cytochrome 450 and flavoprotein nicotinamide adenine nucleotide phosphate in reduced form (NADPH) cytochrome p450 reductase. In humans, aromatase $\mathrm{p} 450$ is found in many tissues and organs, such as: gonads, brain, adipose tissue, placenta, liver, skin, bones, blood vessels, endometrium, as well as in endometrioid heterotopies, in leiomyoma, in endometrial cancer and mammary gland cancer [91; 92]. Timely synthesis of aromatase in the ovarian follicle is responsible for cyclical changes in the level of estradiol in the blood. These changes modulate the structure and function of the female reproductive system and are also required for oocyte maturation, fertilization and implantation. Thus, the timely expression of aromatase in the ovary is critical for the autocrine regulation of folliculogenesis and endocrine control of the reproductive system.

Currently, there are studies evaluating the expression of this enzyme in certain gynecological diseases [93-97]. So, according to the results of Savina normogonadotropic anovulation in patients with external endometriosis and polycystic ovary syndrome is caused by aromatase deficiency in the ovaries and insufficient preovulatory rise in estradiol in the blood $(\mathrm{p}<0.001)$ [93]. Foreign authors also report on the enzyme expression reduction seen in women with external endometriosis [94; 95]. 
Yang et al. investigated the activity of aromatase in the follicular fluids of women diagnosed with polycystic ovaries during controlled ovarian stimulation in IVF cycles $(\mathrm{n}=138)$. As a result, they found lower values of aromatase in follicular fluids of the study group [96]. The same data was reported by Russian scientists [97].

It is interesting to note that the aromatase activity of granulosa cells obtained from pregnant patients after IVF treatment, according to some authors, is significantly higher than in unpregnant patients after transferring the same number of embryos [98]. Moreover, oocytes obtained from follicles with higher follicular fluid estradiol levels had a higher fertilization rate $[99 ; 100]$. The authors agree that the presence of aromatase in granulosa cells plays a fundamental role in follicular maturation, oocyte quality, and successful fertilization $[101 ; 102]$.

At the same time, the nature of p450 ovarian aromatase deficiency is still not fully understood. Some authors point to a defect in the aromatase gene CYP19 among patients with polycystic ovary syndrome treated in IVF cycles [103]. According to other studies, aromatase deficiency may be associated with the hyperproduction of anti-Müllerian hormone by granulosa cells, which, in turn, affects the promoter II of the aromatase p450 CYP19 gene, leading to a decrease in aromatase activity [104]. A number of domestic and foreign authors indicate that the incidence of autoimmune thyroiditis among women seeking help in infertility treatment clinics is significantly higher among patients with concomitant PCOS $[4 ; 9 ; 105]$. It is possible that in case of systemic autoimmune diseases, the immune response is also triggered directly to aromatase leading to the above tendency. This fact deserves the attention of the scientific community and requires further research.

\section{Antibodies to Se-binding protein-1 (SBP-1)}

The existence of autoimmune processes affecting ovarian tissue has long been known. Numerous researchers have identified the presence of antiovarian antibodies associated with premature ovarian failure [106-109] and infertility [110-112]. Antibodies to ovarian antigens comprise a heterogeneous group of autoantibodies directed against the cells of the ovaries. To date, the known antibodies are targeted to follicular cells, granulosa cells, stroma, theca (thecal antibodies) and some other components.

In 2010, a group of American and German scientists discovered a new target for antiovarian antibodies, namely Se-binding protein-1, antibodies to which were detected in $60 \%$ of women with a history of infertility or premature ovarian failure [32]. By nature, SBP1 is a cytoplasmic protein found predominantly in epithelial cells, including those lining the surface of the ovary. It is known that depletion of selenium levels in follicular fluid is associated with idiopathic infertility [113]. In preclinical experimental studies of a contraceptive vaccine containing conjugated SBP1, also known as SP56, a $50 \%$ decrease in the fertility of mice was observed [114].

In a recent study, Yu-Rice et al. found a significantly more frequent presence of antiSBP1 antibodies in the sera of women with ovulatory disorders $(50.0 \%, \mathrm{p}=0.007)$, idiopathic infertility $(24.3 \%, \mathrm{p}=0.02)$ and premature ovarian failure $(28.0 \%, \mathrm{p}=0.02)$ relatively to the control group. Moreover, the same authors noted a more frequent occurrence of antibodies in serous ovarian tumors and suggested that anti-SBP-1 can be used as a predictor of ovarian cancer in the future [115]. This conclusion seems quite logical, given that in a number of experimental studies performed much earlier, the ability of 
SBP1 to suppress tumor growth was noted [116; 117]. Thus, despite the currently limited information on the function and significance of Se-binding protein-1, it can be assumed that autoantibodies to this protein can have a negative effect on female fertility and reproductive potential and, possibly, the effectiveness of infertility treatment within the framework of ART.

\section{Antibodies to mesothelin}

In the world literature, there are limited data on the effect of antibodies to mesothelin on the reproductive failure. It is known that the expression of this protein is increased in ovarian cancers [118], and mesothelin circulating in the blood has a relatively high specificity for ovarian cancer [119-121]. In addition, there is evidence of an increased incidence of antibodies to mesothelin among women with verified ovarian cancer $[122 ; 123]$ and a history of pelvic inflammatory disease [123]. In their study, Luborsky et al. carried out an assessment of mesothelin and antibodies to it in the serum of infertile women in order to identify the relationship between antibodies presence, infertility and the risk of ovarian cancer development in the future. According to the results obtained, antibodies to mesothelin were significantly more often detected in women with ovulatory dysfunction (59\%), premature ovarian failure (44\%), and infertility of unknown origin (25\%) in comparison to the control group. In the course of the study, the authors concluded that these autoantibodies are reliably determined in women with idiopathic infertility and may serve as a predictor of the development of ovarian carcinoma in the future for this group of patients [124]. Based on the revealed relationship between antibodies presence with infertility, it is relevant to perform a study on the role of this marker on the outcomes of ART programs, including embryological stages.

\section{Conclusion}

According to modern concepts, natural and autoimmune antibodies are produced in the human body. It is known that natural antibodies are involved in the formation of a normal immune response and provide homeostasis in organs and body systems. When the mechanisms of self-tolerance are violated, antibodies to own antigens are produced in compliance with the general laws of the humoral immune response. Autoantibodies can be involved in the pathogenesis of organ-specific and systemic autoimmune diseases, serve as harbingers of the disease, and be of great diagnostic value.

Autoimmune diseases are most widespread among women of reproductive age, which is due to the immunostimulatory effect of female sex hormones, the predominance of the Th2 response and the contribution of $\mathrm{X}$ chromosome genes to the immune response. The relationship between autoimmunity and reproduction is of great scientific and practical interest and has been actively studied for over four decades.

Based on the data presented in this review of the literature, autoimmunity can affect all stages of the reproductive process, including oogenesis, implantation and pregnancy. In case of reproductive disorders, organ-specific (antiovarian, antitrophoblastic) and organ-specific (antiphospholipid, antinuclear, antithyroid and others) autoantibodies are determined. Autoantibodies are associated with polycystic ovary syndrome (PCOS), premature ovarian failure (POF), endometriosis, failure of in vitro fertilization cycles, and 
may be responsible for early reproductive failure. It is also known about the combined course of autoimmune processes, an example of which is autoimmune polyglandular syndromes of types 1 and 2. The combined course of autoimmune diseases or asymptomatic carriage of antibodies indicates the common mechanisms of development of various autoimmune pathologies and allows us to make an assumption about "autoimmune reproductive failure syndrome".

The abovementioned indicates the need to develop a line of reproductively significant antibodies in application to direct, cross-over and cumulative assessment of the role of autoimmune antibodies carriage in the implementation of reproductive failures, bearing in mind new approaches to the strategy of overcoming autoimmune reproductive failure.

\section{References}

1. Kuharić M., Rozić D., Karner I. Thyroid Autoimmunity and Infertility. SEEMEDJ, 2017, vol. 1, no. 2, pp. $1-10$.

2. Ombelet W., Cooke I., Dyer S., Serour G., Devroey P. Infertility and the provision of infertility medical services in developing countries. Human Reproduction Update, 2008, vol. 14, no. 6, pp. 605-621.

3. Chen X., Mo M.-L., Huang C.-Y., Diao L.-H., Li G.-G., Li Yu.-Ye., Lerner A., Shoenfeld Y., Zeng Y. Association of serum autoantibodies with pregnancy outcome of patients undergoing first IVF/ICSI treatment: A prospective cohort study. Journal of Reproductive Immunology, 2017, vol. 122, pp. 14-20.

4. Perminova S.G. Infertility in women with thyroid disease: Principles of diagnosis, management. Akusherstvo i ginekologiia: Novosti. Mneniia. Obuchenie, 2013, no. 2, pp. 18-24. (In Russian)

5. ESHRE ART Fact Sheet 2018. Available at: https://www.eshre.eu/Press-Room/Resources (accessed: 20.01.2019).

6. Simon A., Laufer N. Assessment and treatment of repeated implantation failure (RIF). J. Assist. Reprod. Genet. 2012, no. 29, pp. 1227-1239.

7. Unuane D., Velkeniers B., Deridder S., Bravenboer B., Tournaye H., Brucker M.D. Impact of thyroid autoimmunity on cumulative delivery rates in in vitro fertilization/intracytoplasmic sperm injection patients. Fertil. Steril. 2016, no. 106, pp. 144-150.

8. Cline A. M., Kutteh W. H. Is there a role of autoimmunity in implantation failure after in-vitro fertilization? Curr. Opin. Obstet. Gynecol. 2009, no. 21, pp. 291-295.

9. Poppe K., Autin C., Veltri F., Kleynen P., Grabczan L., Rosenberg S., Ameye L. Thyroid Autoimmunity and ICSI Pregnancy Outcomes. J. Clin. Endocrinol. Metab., 2018, no. 103, vol. 5, pp. 1755-1766.

10. Sen A., Kushnir V. A., Barad D. H., Gleicher N. Endocrine autoimmune diseases and female infertility. Nat. Rev. Endocrinol., 2014, no. 10, vol. 1, pp. 37-50.

11. Monteleone P., Parrini D., Faviana P., Carletti E., Casarosa E., Uccelli A., Cela V., Genazzani A. R., Artini P.G. Female infertility related to thyroid autoimmunity: the ovarian follicle hypothesis. Am. J. Reprod. Immunol., 2011, no. 66, vol. 2, pp. 108-114.

12. Chen C. W., Huang Y.L., Tzeng C. R., Huang R. L., Chen C. H. Idiopathic low ovarian reserve is associated with more frequent positive thyroid peroxidase antibodies. Thyroid, 2017, no. 27, vol. 9, pp. 1194-1200.

13. Korevaar Tim I.M., Mínguez-Alarcón L., Messerlian C., Ralph A.de Poortere, Williams P.L., Broeren M. A., Hauser R., Souter I. C. Association of Thyroid Function and Autoimmunity with Ovarian Reserve in Women Seeking Infertility Care. Thyroid, 2018, no. 28, vol. 10, pp. 1349-1358.

14. Sauer R., Roussev R., Jeyendran R. S., Coulam C. B. Prevalence of antiphospholipid antibodies among women experiencing unexplained infertility and recurrent implantation failure. Fertil. Steril., 2010, no. 93, vol. 7, pp. 2441-2443.

15. Backos M., Rai R., Regan L. Antiphospholipid antibodies and infertility. Hum. Fertil., 2002, vol. 5, pp. 30-34.

16. Kikuchi K., Shibahara H., Hirano Y., Kohno T., Hirashima C., Suzuki T., Takamizawa S., Suzuki M. Antinuclear antibody reduces the pregnancy rate in the first IVF-ET treatment cycle but not the cumulative pregnancy rate without specific medication. Am. J. Reprod. Immunol., 2003, no. 50, pp. 363-367. 
17. Taniguchi F. Results of prednisolone given to improve the outcome of in vitro fertilization-embryo transfer in women with antinuclear antibodies. J. Reprod. Med., 2005, no. 50, vol. 6, pp. 383-388.

18. Zhong Y., Ying Y., Wu H., Zhou C., Xu Y., Wang Q., Li J., Shen X., Li J. Relationship between Antithyroid Antibody and Pregnancy Outcome following in Vitro Fertilization and Embryo Transfer. Int. J.Med. Sci., 2012, no. 9, pp. 121-125.

19. Deroux A., Dumestre-Perard C., Dunand-Faure C., Bouillet L., Hoffmann P. Female Infertility and Serum Auto-antibodies: A Systematic Review. Clin. Rev. Allergy Immunol., 2017, no. 53, pp. 78-86.

20. Birkenfeld A., Mukaida T., Minichiello L., Jackson M., Kase N. G., Yemini M. Incidence of autoimmune antibodies in failed embryo transfer cycles. Am. J. Reprod. Immunol., 1994, no. 31, vol. 2-3, pp. 65-68.

21. Geva E., Amit A., Lerner-Geva L., Azem F., Yovel I., Lessing J. B. Autoimmune disorders: another possible cause for in vitro fertilization and embryo transfer failure. Hum. Reprod., 1995, no. 10, pp. 2560 2563.

22. Geva E., Yaron Y., Lessing J. B., Yovel I., Vardinon N., Burke M., Amit A. Circulating autoimmune antibodies may be responsible for implantation failure in in vitro fertilization. Fertil. Steril., 1994, no. 62, pp. 802-806.

23. Cubillos J., Lucena A., Lucena C., Mendoza J.C., Ruiz H., Arango A., Quiroga G., Ferro J., Lucena E. Incidence of autoantibodies in the infertile population. Early Pregnancy, 1997, no. 3, vol. 2, pp. 119-124.

24. Inagaki J., Matsuura E., Nomizu M., Sugiura-Ogasawara M., Katano K., Kaihara K., Kobayashi K., Yasuda T., Aoki K. IgG anti-laminin-1 autoantibody and recurrent miscarriages. Am. J. Reprod. Immunol., 2001, no. 45, pp. 232-238.

25. Ye Y., Kuhn, Kösters M., Arnold G. J., Ishikawa-Ankerhold H., Schulz C., Rogenhofer N., Thaler C. J., Mahner S., Fröhlich T., Jeschke U., von Schönfeldt V. Anti $\alpha$-enolase antibody is a novel autoimmune biomarker for unexplained recurrent miscarriages. EBioMedicine, 2019, no. 41, pp. 610-622.

26. Pala A., Coghi I., Spampinato G., Di Gregorio R., Strom R., Carenza L. Immunochemical and biological characteristics of a human autoantibody to human chorionic gonadotropin and luteinizing hormone. J. Clin. Endocrinol. Metab., 1988, no. 6, vol. 67, pp. 1317-1321.

27. Wass M., McCann K., Bagshawe K. D. Isolation of antibodies to HCG/LH from human sera. Nature, 1978, no. 5669, vol. 274, pp. 369-370.

28. Zou S. H., Yang Z.-Z., Zhang P., Song D.-P., Li B., Wu R.-Y., Cong X. Autoimmune disorders affect the in vitro fertilization outcome in infertile women. Zhonghua Nan Ke Xue. 2008, no. 4, vol. 14, pp. 343-346.

29. Sharif K., Watad A., Bridgewood C., Kanduc D., Amital H., Shoenfeld Y. Insights into the autoimmune aspect of premature ovarian insufficiency. Best Pract. Res. Clin. Endocrinol. Metab, 2019, e:101323.

30. Vega M., Barad D.H., Yu Y., Darmon S. K., Weghofer A., Kushnir V. A., Gleicher N. Anti-mullerian hormone levels decline with the presence of antiphospholipid antibodies. American Journal of Reproductive Immunology, 2016, no. 76, vol. 4, pp. 333-337.

31. Sundblad V., Bussmann L., Chiauzzi V. A., Pancholi V., Charreau E. H. Alpha-enolase: a novel autoantigen in patients with premature ovarian failure. Clin. Endocrinol. (Oxf). 2006, no. 65, pp. 745-751.

32. Edassery S. L., Shatavi S. V., Kunkel J.P., Hauer C., Brucker C., Penumatsa K., Yu Y., Dias J. A., Luborsky J.L. Autoantigens in ovarian autoimmunity associated with unexplained infertility and premature ovarian failure. Fertil. Steril., 2010, no. 94, vol. 7, pp. 2636-2641.

33. Yu-Rice Y., Edassery S. L., Urban N., Hellstrom I., Hellstrom K. E., Deng Y., Li Y., Luborsky J. L. Selenium-Binding Protein 1 (SBP1) autoantibodies in ovarian disorders and ovarian cancer. Reproduction, 2017, no. 153, vol. 3, pp. 277-284.

34. Luborsky J.L., Yu Y., Edassery S. L., Jaffar J., Yip Yu. Ye., Liu P., Hellstrom K. E., Hellstrom I. Autoantibodies to mesothelin in infertility. Cancer Epidemiol Biomarkers Prev., 2011, vol. 20, iss. 9, pp. 1970-1978.

35. Miko E., Meggyes M., Doba K., Farkas N., Bogar B., Barakonyi A., Szereday L., Szekeres-Barto J., Mezosi E. Characteristics of peripheral blood NK and NKT-like cells in euthyroid and hypothyroid women with autoimmunity, experiencing reproductive failure. J. Reprod. Immunol., 2017, no. 124, pp. 62-70.

36. Sher G., Fisch J. D., Maassarani G., Matzner W., Ching W., Chong P. Antibodies to phosphatidylethanolamine and phosphatidylserine are associated with increased natural killer cell activity in non-male factor infertility patients. Hum. Reprod., 2000, no. 15, pp. 1932-1936.

37. Fadeev V.V. According to the clinical recommendations of American thyroid association in thyroid pathology diagnosis and treatment during pregnancy and postpartum. Clinical and experimental thyroidology, 2012, no. 1, vol. 8, pp. 7-18. 
38. De Carolis C., Greco E., Guarino M. Antityroid antibodies and antiphospholipid syndrome: evidence of reduced fecundity and of poor pregnancy outcome in recurrent spontaneous abortions. Am. J. Reprod. Immunol., 2004, no. 52, pp. 263-266.

39. Lee Y. L., Ng H. P., Lau K. S., Liu W. M., O W. S., Yeung W. S. B., Kung A. W. C. Increased fetal abortion rate in autoimmune thyroid disease is related to circulating TPO autoantibodies in an autoimmune thyroiditis animal model. Fertil. Steril., 2009, vol. 91, iss. 5, pp. 2104-2109.

40. Vissenberg R., Manders U. D., Mastenbroek S., Fliers E., Afink G. B., Ris-Stalpers C., Goddijn M., Bisschop P.H. Pathophysiological aspects of thyroid hormone disorder/thyroid peroxidase autoantibodies and reproduction. Hum. Reprod. Update, 2015, no. 21, vol. 3, pp. 378-387.

41. Weghofer A., Himaya E., Kushnir V. A., Barad D. H., Gleicher N. The impact of thyroid function and thyroid autoimmunity on embryo quality in women with low functional ovarian reserve: a case-control study. Reprod. Biol. Endocrinol., 2015, no. 13, vol. 1, pp. 43-49.

42. Matalon S. T., Blank M., Levy Y., Carp H. J. A., Arad A., Burek L., Grunebaum E., Sherer Y., Ornoy A., Refetoff S., Weiss R.E., Rose N. R., Shoenfeld Y. The pathogenic role of anti-thyroglobulin antibody on pregnancy: evidence from an active immunization model in mice. Human Reproduction, 2003, no. 18, vol. 5, pp. 1094-1099.

43. Medenica S., Garalejia E., Arsic B., Medjo B., Bojovic Jovic D., Abazovic D., Vukovic R., Zarkovic M. Follicular fluid thyroid autoantibodies, thyrotropin, free thyroxine levels and assisted reproductive technology outcome. PLOS ONE, 2018, no. 13, vol. 10, pp. e0206652.

44. Busnelli A., Paffoini A., Luigi F., Somigliana E. The impact of thyroid autoimmunity on IVF/ICSI outcome: a systematic review and meta-analysis. Human Reproduction Update, 2016, no. 22, vol. 6, pp. 775-790.

45. Ruiz-Irastorza G., Crowther M., Branch W., Khamastha M. A. Antiphopholipid syndrome. Lancet, 2010, no. 376, pp. 1498-1509.

46. Cervera R., Boffa M. C., Khamastha M. A., Hughes G. R. V. The Euro Phospholipid project: epidemiology of the antiphopholipid syndrome in Europe. Lupus, 2009, no. 18, pp. 889-893.

47. Silver R. M., Parker C. B., Reddy U. M., Goldenberg R., Coustan D., Dudley D. J., Saade G. R., Stoll B., Koch M. A., Conway D., Bukowski R., Rowland Hogue C. J., Pinar H., Moore J., Willinger M., Ware Branch D. Antiphospholipid Antibodies in Stillbirth. Obstet. Gynecol., 2013, no. 122, pp. 641-657.

48. Heilmann L., Schorsch M., Hahn T., Fareed J. Antiphospholipid syndrome and pre-eclampsia. Semin. Thromb. Hemost., 2011, no. 37, pp. 141-145.

49. Di Prima F. A. F., Valenti O., Hyseni E., Giorgio E., Faraci M., Renda E., De Domenico R., Monte S. Antiphospholipid Syndrome during pregnancy: The state of the art. J. Prenat. Med., 2011, no. 5, pp. 41-53.

50. Gleicher N., El-Roeiy A. The reproductive autoimmune failure syndrome. Am. J. Obstet. Gynecol., 1988, no. 159, pp. 223-227.

51. Blank M., Cohen J., Toder V., Shoenfeld Y. Induction of anti-phospholipid syndrome in naive mice with mouse lupus monoclonal and human polyclonal anti-cardiolipin antibodies. Proc. Natl. Acad. Sci. USA, 1991, no. 88, vol. 8, pp. 3069-3073.

52. Kaider B. D., Coulam C. B., Roussev R. G. Murine embryos as a direct target for some human autoantibodies in vitro. Human Reproduction, 1999, no. 14, pp. 2556-2561.

53. Sthoeger Z.M., Mozes E., Tartakovsky B. Anti-cardiolipin antibodies induce pregnancy failure by impairing embryonic implantation. Proceedings National Academy of Sciences USA, 1993, no. 90, pp. 6464-6467.

54. Tartakovsky B., Bermas B. L., Sthoeger Z., Shearer G. M., Mozes E. Defective maternal-fetal interaction in a murine autoimmune model. Human Reproduction, 1996, no. 11, pp. 2408-2411.

55. Parr M. B., Parr E. L. Immunohistochemical localization of immunoglobulins A, G and M in the mouse female genital tract. J. Reprod. Fert., 1985, no. 74, pp. 361-370.

56. Azem F., Geva E., Amit A., Lerner-Geva L., Schwartz T., Ben-Yosef T., et al. High levels of anticardiolipin antibodies in patients with abnormal embryo morphology who attended an in vitro fertilization program. Am. J. Reprod. Immunol., 1998, no. 39, pp. 161-163.

57. Matsubayashi H., Sugi T., Arai T., Shida M., Kondo A., Suzuki T., Izumi S., McIntyre J. A. IgG-antiphospholipid antibodies in follicular fluid of IVF-ET patients are related to low fertilization rate of their oocytes. Am. J. Reprod. Immunol., 2006, no. 55, vol. 5, pp. 341-348.

58. Coulam C.B., Roussev R. Chemical pregnancies: immunologic and ultrasonographic studies. Am. J. Reprod. Immunol., 2002, no. 48, vol. 5, pp. 323-328.

59. Di Simone N., Di Nicuolo F., D’Ippolito S., Castellani R., Tersigni C., Caruso A., Meroni P., Marana R. Antiphospholipid antibodies affect human endometrial angiogenesis. BiolReprod., 2010, no. 83, pp. 212-219. 
60. D’Ippolito S., Meroni P. L., Koike T., Veglia M., Scambia G., Di Simone N. Obstetric antiphospholipid syndrome: A recent classification for an old defined disorder. Autoimmunity Reviews, 2014, no. 13, pp. 901-908.

61. Ahmed N., Shigidi M., Al Agib A. N., Abdelrahman H., Taha E. Clinical features and antinuclear antibodies profile among adults with systemic lupus erythematosus and lupus nephritis: A cross-sectional study. Pan. Afr. Med. J.2017, no. 27, p. 114.

62. Ehrenstein M.R. Antinuclear antibodies and lupus: Causes and consequences. Rheumatology, 1999, no. 38, pp. 691-693.

63. Kuwana M. Circulating Anti-Nuclear Antibodies in Systemic Sclerosis: Utility in Diagnosis and Disease Subsetting. J. Nippon Med. Sch. Nippon Ika Daigaku Zasshi, 2017, no. 84, pp. 56-63.

64. Menor Almagro R., Rodríguez Gutiérrez J.F., Martín-Martínez M. A., Rodríguez Valls M. J., Aranda Valera C., de la Iglesia Salgado J. L. Association between antinuclear antibody titers and connective tissue diseases in a Rheumatology Department. Reumatol. Clin., 2017, no. 13, pp. 150-155.

65. Ravelli A., Felici E., Magni-Manzoni S., Pistorio A., Novarini C. Bozzola E., Viola S., Martini A. Patients with antinuclear antibody-positive juvenile idiopathic arthritis constitute a homogeneous subgroup irrespective of the course of joint disease. Arthritis Rheum., 2005, no. 52, pp. 826-832.

66. Zachou K., Rigopoulou E., Dalekos G. N. Autoantibodies and autoantigens in autoimmune hepatitis: Important tools in clinical practice and to study pathogenesis of the disease. J. Autoimmune Dis., 2004, no. 1, p. 2 .

67. Kaider A.S., Kaider B. D., Janowicz P. B., Roussev R. G. Immunodiagnostic evaluation in women with reproductive failure. Am. J. Reprod. Immunol., 1999, no. 42, vol. 6, pp. 335-346.

68. Lucena E., Cubillos J. Immune abnormalities in endometriosis comprising infertility in IVF patients. J. Reprod. Med., 1999, no. 44, pp. 458-464.

69. Ying Y., Zhong Y., Zhou C., Xu Y., Wang Q., Li J., Shen X., Wu H. Antinuclear antibodies predicts a poor IVF-ET outcome: Impaired egg and embryo development and reduced pregnancy rate. Immunol. Investig., 2012, no. 41, pp. 458-468.

70. Kaider B. D., Coulam C. B., Roussev R. G. Murine embryos as a direct target for some human autoantibodies in vitro. Hum. Reprod., 1999, no. 14, vol. 10, pp. 2556-2561.

71. Sthoeger Z., Mozes E., Tartakovsky B. Anti-cardiolipin antibodies induce pregnancy failure by impairing embryonic implantation. Proc. Natl. Acad. Sci. USA, 1993, no. 90, pp. 6464-6467.

72. Simerly C., Balczon R., Brinkley B. R. Microinjected kinetochore antibodies interfere with chromosome movement in meiotic and mitotic mouse oocytes. J Cell Biol. 1990, no. 111, pp. 1491-1504.

73. Ying Y., Zhong Y.P., Zhou C. Q., et al. A further exploration of the impact of antinuclear antibodies on in vitro fertilization-embryo transfer outcome. Am. J. Reprod. Immunol., 2013, no. 70, vol. 3, pp. 221-229.

74. Fan J., Zhong Y., Chen C. Impacts of Anti-dsDNA Antibody on In Vitro Fertilization-Embryo Transfer and Frozen-Thawed Embryo Transfer. J. Immunol. Res., 2017, e:8596181.

75. Li Y., Wang Y., Ma Y., Lan Y., Jia C., Liang Y., Wang S. Investigation of the impact of antinuclear antibody on the outcome of in vitro fertilization/intracytoplasmic sperm injection treatment. Taiwan. J. Obstet. Gynecol., 2015, no. 54, pp. 742-748.

76. Zhu Q., Wu L., Xu B., Hu M.-H., Tong X.-H., Ji J.-J., Liu Y.-S. A retrospective study on IVF/ICSI outcome in patients with anti-nuclear antibodies: The effects of prednisone plus low-dose aspirin adjuvant treatment. Reprod. Biol. Endocrinol., 2013, no. 11, p. 98.

77. Burgeson R.E., Chiquet M., Deutzmann R., Ekblom P., Engel J., Kleinman H. K., Martin G. R., Meneguzzi G., Paulsson M., Sanes J. A new nomenclature for the laminins. Matrix Biol., 1994, no. 14, pp. 209-211.

78. Foidart J. M., Yaar M., Figueroa A., Wilk A., Brown K. S., Liotta L. A. Abortion in mice induced by intravenous injections of antibodies to type IV collagen or laminin. Am. J.Pathol., 1983, no. 10, pp. 346-357.

79. Korhonen M., Virtanen I. Immunohistochemical localization of laminin and fibronectin isoforms in human placental villi. J. Histochem. Cytochem., 2001, no. 49, pp. 313-322.

80. Carey S. W., Klein N.W. Autoantibodies to laminin and other basement membrane proteins in sera from monkeys with histories of reproductive failure identified by cultures of whole rat embryos. Fertil. Steril., 1989, no. 51, pp. 711-718.

81. Matalon S. T., Blank M., Matsuura E., Inagaki J., Nomizu M., Levi Y., Koike T., Shere Y., Ornoy A., Shoenfeld Y. Immunization of naive mice with mouse laminin-1 affected pregnancy outcome in a mouse model. Am. J. Reprod. Immunol., 2003, no. 50, pp. 159-165. 
82. Inagaki J., Sugiura-Ogasawara M., Nomizu M., Nakatsuka M., Ikuta K., Suzuki N., Kaihara K., Kobayashi K., Yasuda T., Shoenfeld Y., Aoki K., Matsuura E. An association of IgG antilaminin-1 autoantibodies with endometriosis in infertile patients. Hum. Reprod., 2003, no. 18, pp. 544-549.

83. Caccavo D., Pellegrino N. M., Totaro I., Vacca M.P., Selvaggi L., Depalo R. Anti-laminin-1 antibodies in sera and follicular fluid of women with endometriosis undergoing in vitro fertilization. International Journal of Immunopathology and Pharmacology, 2011, no. 24, pp. 481-488.

84. Caccavo D., Pellegrino N. M, Nardelli C., Vergine S., Leone L., Marolla A., Vacca M. P., Depalo R. Antilaminin- 1 antibodies in serum and follicular fluid of women with Hashimoto's thyroiditis undergoing in vitro fertilization. Int. J. Immunopathol. Pharmacol., 2016, no. 29, vol. 2, pp. 280-287.

85. Bae S., Kim H., Lee N., Won C., Kim H. R., Hwang Y. I., Song Y. W., Kang J. S., Lee W. J. Alpha-enolase expressed on the surfaces of monocytes and macrophages induces robust synovial inflammation in rheumatoid arthritis. J. Immunol., 2012, no. 189, vol. 1, pp. 365-372.

86. Sarapik A., Haller-Kikkatalo K., Utt M., Teesalu K., Salumets A., Uibo R. Serum antiendometrial antibodies in infertile women - potential risk factor for implantation failure. Am. J. Reprod. Immunol., 2010, no. 63, vol. 5, pp. 349-357.

87. Walter M., Berg H., Leidenberger F. A., Schweppe K. W., Northemann W. Autoreactive epitopes within the human alpha-enolase and their recognition by sera from patients with endometriosis. J. Autoimmun., 1995, no. 8, vol. 6, pp. 931-945.

88. Amato F., Warnes G. M., Kirby C.A., Norman R. J. Infertility caused by hCG autoantibody. J. Clin. Endocrinol. Metab., 2002, no. 3, vol. 87, pp. 993-997.

89. Sidel'nikova V.M. Reccurent pregnancy loss. Triada-X, 2005, p. 304. (In Russian)

90. Zou S. H., Yang Z.-Z., Zhang P., Song D.-P., Li B., Wu R.-Y., Cong X. Autoimmune disorders affect the in vitro fertilization outcome in infertile women. Zhonghua Nan Ke Xue, 2008, no. 4, vol. 14, pp. 343-346.

91. Simpson E. R. Biology of aromatase in the mammary gland. J. Mammary Gland Biol. Neoplasia, 2000, no. 3, vol. 5, pp. 251-258.

92. Toda K., Simpson E. R., Mendelson C.R., Shizuta Y., Kilgore M. W. Expression of the gene encoding aromatase cytochrome P450 (CYP19) in fetal tissues. Mol. Endocrinol., 1994, no. 2, vol. 8, pp. 210-217.

93. Savina V. A. Ovarian aromatase $\mathrm{p} 450$ and normogonadotropic ovarian deficiency. Journal of Obstetrics and Women's Diseases, 2012, no. 61, vol. 1, pp. 84-89. (In Russian)

94. Hosseini E., Mehraein F., Shahhoseini M., Karimian L., Nikmard F., Ashrafi M., Afsharian P., Aflatoonian R. Epigenetic alterations of CYP19A1 gene in Cumulus cells and its relevance to infertility in endometriosis. J. Assist. Reprod. Genet., 2016, no. 33, vol. 8, pp. 1105-1113.

95. Barcelos I.D., Donabella F.C., Ribas C.P., Meola J., Ferriani R. A., Paro de Paz C. C., Navarro P. A. Down-regulation of the CYP19A1 gene in cumulus cells of infertile women with endometriosis. Reprod. Biomed Online, 2015, no. 30, vol. 5, pp. 532-541.

96. Yang F., Ruan Y.C., Yang Y.J., Wang K., Liang S.-S., Han Y.-B., Teng X.-M., Yang J.-Z. Follicular hyperandrogenism downregulates aromatase in luteinized granulosa cells in polycystic ovary syndrome women. Reproduction, 2015, no. 150, vol. 4, pp. 289-296.

97. Savina V.A., Kvetnoy I. M., Kleshhev M. A., Potin V. V., Rulev V. V., Tarasova M. A., Tkachenko N. N., Yarmolinskaia M.I. Ovarian aromatase p450 in polycystic ovary syndrome. Med. Akad. Z., 2012, no. 12, vol. 1, pp. 66-72. (In Russian)

98. Neal M. S., Younglai E. V., Holloway A.C., Foster W. G. Aromatase activity in granulosa cells as a predictor of pregnancy potential. Int. Congr. Ser., 2004, no. 1271, pp. 139-142.

99. Carpintero N. L., Suarez O. A., Mangas C. C., Varea C. G., Rioja R. G. Follicular steroid hormones as markers of oocyte quality and oocyte development potential. J.Hum. Reprod. Sci., 2014, no. 7, vol. 3, pp. 187-193.

100. Lamb J.D., Zamah A.M., Shen S., McCulloch C., Cedars M.I., Rosen M.P. Follicular fluid steroid hormone levels are associated with fertilization outcome after intracytoplasmic sperm injection. Fertil. Steril., 2010, no. 94, vol. 3, pp. 952-957.

101. Hamel M., Dufort I., Robert C., Gravel C., Leveille M.-C., Leader A., Sirard M.-A. Identification of differentially expressed markers in human follicular cells associated with competent oocytes. Hum. Reprod., 2008, no. 23, vol. 5, pp. 1118-1127.

102. Revelli A., Canosa S., Bergandi L., Skorokhod O. A., Biasoni V., Carosso A., Bertagna A., Maule M., Aldieri E., Diletta D'Eufemia M. D., Evangelista F., Colacurci N., Benedetto C. Oocyte polarized light microscopy, assay of specific follicular fluid metabolites, and gene expression in cumulus cells as different approaches to predict fertilization efficiency after ICSI. Reprod. Biol. Endocrinol., 2017, no. 15, vol. 1, p. 47. 
103. Lazaros L., Xita N., Hatzi E., Takenaka A., Kaponis A., Makrydimas G., Sofikitis N., Stefos T., Zikopoulos K., Georgiou I. CYP19 gene variants affect the assisted reproduction outcome of women with polycystic ovary syndrome. Gynecol. Endocrinol., 2013, no. 29, vol. 5, pp. 478-482.

104. Pellatt L., Rice S., Dilaver N., Heshri A., Galea R., Brincat M., Brown K., Simpson E. R., Mason H.D. Anti-Müllerian hormone reduces follicle sensitivity to folliclestimulating hormone in human granulosa cells. Fertil. Steril., 2011, no. 5, vol. 96, pp. 1246-1314.

105. Janssen O. E., Mehlmauer N., Hahn S., Offner A. H., Gärtner R. High prevalence of autoimmune thyroiditis in patients with polycystic ovary syndrome. Eur. J. Endocrinol., 2004, no. 150, vol. 363-369.

106. Forges T., Monnier-Barbarino P., Faure G. C., Bene M. C. Autoimmunity and antigenic targets in ovarian pathology. Hum. Reprod. Update, 2004, no. 10, vol. 2, pp. 163-175.

107. Tuohy V.K., Altuntas C.Z. Autoimmunity and premature ovarian failure. Curr. Opin. Obstet. Gynecol., 2007, no. 19, vol. 4, pp. 366-369.

108. Damewood M. D., Zacur H. A., Hoffman G. J., Rock J. A. Circulating antiovarian antibodies in premature ovarian failure. Obstet. Gynecol., 1986, no. 68, vol. 6, pp. 850-854.

109. Fenichel P., Sosset C., Barbarino-Monnier P., Gobert B., Hieronimus S., Bene M., et al. Prevalence, specificity and significance of ovarian antibodies during spontaneous premature ovarian failure. Hum. Reprod., 1997, no. 12, vol. 12, pp. 2623-2628.

110. Meyer W.R., Lavy G., DeCherney A.H., Visintin I., Economy K., Luborsky J.L. Evidence of gonadal and gonadotropin antibodies in women with a suboptimal ovarian response to exogenous gonadotropin. Obstet. Gynecol., 1990, no. 75, vol. 5, pp. 795-799.

111. Luborsky J., Llanes B., Davies S., Binor Z., Radwanska E., Pong R. Ovarian autoimmunity: greater frequency of autoantibodies in premature menopause and unexplained infertility than in the general population. Clin. Immunol., 1999, no. 90, vol. 3, pp. 368-374.

112. Gzgzyan A. M. Autoimmune hypogonadism (pathogenesis, diagnosis, treatment). Dr. Sci. thesis. 2007. (In Russian)

113. Paszkowski T., Traub A.I., Robinson S. Y., McMaster D. Selenium dependent glutathione peroxidase activity in human follicular fluid. Clin. Chim. Acta, 1995, no. 236, vol. 2, pp. 173-180.

114. Hardy C. M., Clydesdale G., Mobbs K. J. Development of mouse-specific contraceptive vaccines: infertility in mice immunized with peptide and polyepitope antigens. Reproduction, 2004, no. 128, vol. 4, pp. 395-407.

115. Yu-Rice Y., Edassery S. L., Urban N., Hellstrom I., Hellstrom K. E., Deng Y., Li Y., Luborsky J. L. Selenium-Binding Protein 1 (SBP1) autoantibodies in ovarian disorders and ovarian cancer. Reproduction, 2017, no. 153, vol. 3, pp. 277-284.

116. Fang W., Goldberg M. L., Pohl N. M., Bi X., Tong C., Xiong B., Koh T. J., Diamond A. M., Yang W. Functional and physical interaction between the selenium-binding protein 1 (SBP1) and the glutathione peroxidase 1 selenoprotein. Carcinogenesis, 2010, no. 31, pp. 1360-1366.

117. Pohl N. M., Tong C., Fang W., Bi X., Li T., Yang W. Transcriptional regulation and biological functions of selenium-binding protein 1 in colorectal cancer in vitro and in nude mouse xenografts. PLoS One, 2009, no. 4, e:7774.

118. Rosen D. G., Wang L., Atkinson J. N., Yu Y., Lu K.H., Diamandis E.P., Hellstrom I., Mok S.C., Liu J., Bast R. C. Jr. Potential markers that complement expression of CA125 in epithelial ovarian cancer. Gynecol. Oncol., 2005, no. 99, pp. 267-277.

119. Scholler N., Fu N., Yang Y., Ye Z., Goodman G.E., Hellstrom K. E., Hellström I. Soluble member(s) of the mesothelin/megakaryocyte potentiating factor family are detectable in sera from patients with ovarian carcinoma. Proc. Natl. Acad. Sci. USA, 1999, no. 96, pp. 11531-11536.

120. McIntosh M. W., Drescher C., Karlan B., Scholler N., Urban N., Hellstrom K. E., Hellstrom I. Combining CA 125 and SMR serum markers for diagnosis and early detection of ovarian carcinoma. Gynecol. Oncol., 2004, no. 95, pp. 9-15.

121. Palmer C., Duan X., Hawley S., Scholler N., Thorpe J.D., Sahota R.A., Wong M. Q., Wray A., Bergan L. A., Drescher C. W., McIntosh M. W., Brown P. O., Nelson B. H., Urban N. Systematic evaluation of candidate blood markers for detecting ovarian cancer. PLoS ONE, 2008, no. 3, pp. e2633.

122. Ho M., Hassan R., Zhang J., Wang Q. C., Onda M., Bera T., Pastan I. Humoral immune response to mesothelin in mesothelioma and ovarian cancer patients. Clin. Cancer Res., 2005, no. 11, pp. 38143820 .

123. Hellstrom I., Friedman E., Verch T., Yang Y., Korach J., Jaffar J., Swisher E., Zhang B., Ben-Baruch G., Tan M. C. B., Goedegebuure P., Hellstrom K. E. Anti-mesothelin antibodies and circulating mesothelin relate to the clinical state in ovarian cancer patients. Cancer Epidemiol. Biomarkers Prev., 2008, no. 17, pp. 1520-1526. 
124. Luborsky J. L., Yu Y., Edassery S. L., et al. Autoantibodies to mesothelin in infertility. Cancer Epidemiol. Biomarkers Prev., 2011, no. 20, vol. 9, pp. 1970-1978.

Received: November 25, 2020

Accepted: January 15, 2021

Authors' information:

Galina Kh.Safarian _ Postgraduate Student; Galasaf07@gmail.com Alexandr M. Gzgzyan - MD, Dr. Sci. (Medicine), Professor; agzgzyan@hotmail.com Lyailya Kh. Dzhemlikhanova - MD, PhD, Associate Professor; dzhemlikhanova_l@mail.ru Darico A. Niauri - MD, Dr. Sci. (Medicine), Professor; d.niauri@mail.ru Alexandra V.Znobishina - Clinical Resident; sasha30049696@gmail.com Yelena S. Borodina - Postgraduate Student; lena.borodina9@yandex.ru Nguyen Cong Tuan — Postgraduate Student; dr.tuan99999@gmail.com 